\title{
Sustentabilidade premiada: mudanças observadas entre organizações vencedoras do Prêmio Braztoa de Sustentabilidade em Turismo
}

\author{
Awarded sustainability: observed changes among winners of the Braztoa Award of \\ Sustainability in Tourism
}

Sostenibilidad premiada: cambios observados entre organizaciones ganadoras del Premio Braztoa de Sostenibilidad en Turismo

\author{
Luanna Suellen Lourdes dos Santos ${ }^{1}$ \\ Helena Araújo Costa ${ }^{2}$ \\ Solange Alfinito ${ }^{3}$
}

Este artigo foi recebido em 22 de JUNHO de 2018 e aprovado em 25 de JANEIRO de 2019

Resumo: As premiações de sustentabilidade são vistas como um estímulo para que organizações continuem praticando ações mais sustentáveis e como um mecanismo, sobretudo, para aumentar a credibilidade na comunicação com clientes. Assim, neste estudo, objetiva-se analisar as mudanças observadas entre organizações vencedoras do Prêmio Braztoa de Sustentabilidade no Turismo, de 2012 a 2016. Para isso, apura-se a visão de gestores sobre a situação atual das iniciativas premiadas e de suas organizações, as mudanças ocorridas em relação a estratégia, desempenho, clientes, concorrentes, fornecedores, parceiros e colaboradores, e a influência do Prêmio para tais mudanças. O referencial teórico é composto por conceitos que articulam turismo, sustentabilidade, responsabilidade e ecolabels, com foco nas premiações. A metodologia tem abordagem quantitativa por meio de survey on-line, com adesão de 22 respondentes. Os dados primários são analisados pelo uso de estatística descritiva e inferencial. Observa-se que, praticamente, a totalidade das empresas aprimora ou mantém as iniciativas após a premiação. As mudanças percebidas pelas vencedoras dizem mais respeito a aspectos estratégicos, de cultura interna e de planejamento do que a vendas e faturamento. Revela-se ainda que a maioria das mudanças investigadas é atribuída ao Prêmio. Dois conjuntos de mudanças são identificados como mais relevantes: um ligado ao mercado consumidor (os clientes), e outro, a stakeholders (fornecedores, parceiros). Ambos fortalecem a visão de que o Prêmio analisado contribui para o fortalecimento de premissas de sustentabilidade na atuação das organizações vencedoras em diferentes aspectos e níveis.

Palavras-chave: premiações, sustentabilidade, turismo sustentável

Abstract: The sustainability awards consist on a stimulus for the continuity of a series of sustainable actions and as a mechanism to increase the credibility in the organizational communication with its clients. Thus, this study aims to analyse the changes observed among the winners of the Braztoa Award of Sustainability in Tourism from 2012 to 2016. To accomplish that goal, there were investigated the changes that have occurred in the winning initiatives and their organizations in relation to the strategy, performance, customers, competitors, suppliers, partners and employees, as

\footnotetext{
Graduação em Administração pela Universidade de Brasília - UNB, Brasília/DF, Brasil E-mail: luanna.suellen19@gmail.com.

${ }^{2}$ Doutora em Desenvolvimento Sustentável pelo Centro de Desenvolvimento Sustentável da Universidade de Brasília — UNB, Brasília/DF, Brasil.E-mail: helenacosta@unb.br.

${ }^{3}$ Pós-doutoranda em Marketing e Sustentabilidade pelo Department of Management da Aarhus University, Dinamarca. Universidade de Brasília — UNB, Brasília/DF, Brasil.E-mail: solange.alfinito@gmail.com.
} 
well as the influence of the awards for such changes. The theoretical framework was composed of concepts that articulate tourism, sustainability, responsibility and ecolabels, focusing on the awards. The methodology consisted on a quantitative approach through an online survey of 22 respondents. The primary data were analysed used using descriptive and inferential statistics. The results indicated that most organizations kept or broadened the awarded initiative. The perceived changes are more related to strategic aspects, internal culture and planning than sales and revenue. It was also revealed that most of the changes investigated were attributed to the award. Two sets of changes were identified as more relevant, one linked to the market (customers) and the second linked to other stakeholders (suppliers, partners). Both reveals that the analysed award contributed to strengthening the adoption of sustainability by the winning organizations in different aspects and levels.

Key words: ecolabels, awards, sustainability, sustainable tourism

Resumen: Las premiaciones de sostenibilidad se ven como un estímulo para que organizaciones continúen practicando acciones más sostenibles y como un mecanismo para aumentar la credibilidad en la comunicación con los clientes. Así, este estudio objetivó analizar los cambios observados entre organizaciones ganadoras del Premio Braztoa de Sostenibilidad en Turismo de 2012 a 2016. Para tanto se verificó la visión de gestores sobre la situación actual de las iniciativas premiadas y de sus organizaciones, los cambios ocurridos en relación con la estrategia, desempeño, clientes, competidores, proveedores, socios y colaboradores así como y la influencia del Premio para tales cambios. El referencial teórico fue compuesto por conceptos que articulan turismo, sostenibilidad, responsabilidad y ecolabels, con foco en las premiaciones. La metodología tuvo un enfoque cuantitativo a través de encuestas online con adhesión de 22 respondientes. Los datos primarios se analizaron con el uso de estadística descriptiva e inferencial. Se observó que prácticamente la totalidad de las empresas mejoraron o mantuvieron las iniciativas después de la premiación. Los cambios percibidos por las ganadoras se refirieron más a aspectos estratégicos, de cultura interna y de planificación, que a ventas y facturación. Se reveló que la mayoría de los cambios investigados fueron atribuidos al Premio. Dos conjuntos de cambios se identificaron como más relevantes, siendo uno vinculado al mercado consumidor (los clientes) y otro vinculado a otros stakeholders (proveedores, socios). Ambos fortalecen la visión de que el premio analizado contribuyó al fortalecimiento de premisas de sostenibilidad en la actuación de las organizaciones vencedoras en diferentes aspectos y niveles.

Palabras clave: premios, sostenibilidad, turismo sostenible

\section{Introdução}

Em diversos setores da economia, a atividade humana causa, em maior ou menor grau, impactos aos recursos naturais, fazendo com que haja discussões quanto a como proceder para que esses impactos se tornem, pouco a pouco, menos maléficos em relação aos bens comuns (ROCHA, 2011). Ainda, com a consolidação das democracias, a abertura de fronteiras comerciais e o desenvolvimento tecnológico que facilitou demasiadamente a obtenção de informações (ALMEIDA, 2002; SOBRAL, 2007), a sociedade tornou-se mais consciente da impossibilidade de separar o 
desenvolvimento econômico das degradações socioambientais que ocorrem em torno do globo (RELATÓRIO BRUNDTLAND, 1987).

Partindo dessa óptica, o setor de turismo está em evidência, em virtude de sua representatividade na atualidade, chegando a um total de 10,2\% do PIB mundial, isto é, uma arrecadação de US\$ 7,6 trilhões (WTTC, 2017). Essa é uma atividade em que a preocupação com a sustentabilidade é fundamental, pois, como qualquer outra, pode trazer tanto impactos positivos, como negativos para a comunidade receptora e o meio ambiente (CHEHADE et al., 2009).

Ainda que não haja um consenso entre autores sobre o real impacto do comportamento responsável das empresas para os consumidores, grupo no qual se podem incluir os turistas (LENZIARDI et al., 2010; MOHR et al., 2001; SERPA e FOURNEAU, 2007), são crescentes os esforços empresariais para realizar ações e comunicá-las à sociedade (FONT e TRIBE, 2001). Encontram-se esforços nesse setor com o propósito de analisar e implementar políticas e estratégias organizacionais que racionalizem o uso dos recursos naturais, com maior inclusão das comunidades, por meio da geração de empregos e valorização das culturas locais (COSTA, 2013; ROCHA, 2011).

Baseando-se nisso, na tentativa de identificar quais são as organizações inseridas em ações de sustentabilidade, houve a necessidade da criação de mecanismos de rotulagem ambiental - como selos, rótulos, certificações, códigos voluntários e prêmios — as chamadas ecolabels (BUCKLEY, 2002; SASIDHARAN et al., 2002; FONT, 2002; PRIETO-SANDOVAL et al., 2016; GOODWIN, 2011). Elas são entendidas como rótulos que podem comunicar a identidade da marca, influenciar o comportamento do consumidor e informar os públicos-alvo sobre condutas socioambientais, possibilitando uma comunicação esclarecida quanto a princípios e ações exercidas no mundo corporativo em favor da sustentabilidade ((BARBOSA et al., 2017; FONT et al., 2016; BUCKLEY, 2002).

No turismo, as premiações voltadas para a sustentabilidade turística são vistas como meios de reconhecimento de iniciativas benéficas para o meio ambiente e para a sociedade, trazendo inspiração para o desenvolvimento do setor, por meio da inovação e do conhecimento, desde o nível local até o internacional (UNWTO, 2017). Espera-se uma série de benefícios com base nessas premiações, seja no âmbito setorial, empresarial ou no dos consumidores (KOZAK e NIELD, 2004; SASIDHARAN et al., 2002; FONT e TRIBE, 2001), tornando-as fundamentais para a melhora dos pontos estratégicos da organização, como o de relacionamento com stakeholders, desempenho e planejamento estratégico (GOODWIN, 2011). 
MUDANÇAS OBSERVADAS EM

ORGANIZAÇÕES VENCEDORAS DO PRÊMIO

BRAZTOA DE SUSTENTABILIDADE EM

TURISMO
Luanna Suellen Lourdes dos Santos

Helena Araújo Costa

Solange Alfinito

Todavia os estudos acerca das ecolabels apresentam lacunas. Entre eles, o fato de, repetidamente, estarem atentos apenas a questões ambientais, e não à sustentabilidade como um todo (AYUSO, 2007). As abordagens, via de regra, voltam-se para as metodologias das premiações (FONT, 2002), ou para o impacto das ecolabels na decisão de compra e/ou na comunicação com o turista (BUCKLEY, 2002; SASIDHARAN et al., 2002; FONT, 2002). Uma análise da literatura evidencia que as premiações são as ecolabels menos investigadas, e, entre os estudos voltados para o tema, não foi encontrado nenhum que colocasse ênfase nas mudanças que elas provocam nas organizações premiadas. Dessa forma, permanece a lacuna, apontada por Golden (2010), quando afirma que há carência de monitoramento dos benefícios das próprias ecolabels.

Assim, o objetivo geral do presente artigo consiste em analisar as mudanças observadas entre organizações vencedoras do Prêmio Braztoa de Sustentabilidade no Turismo durante o período de sua vigência - 2012 a 2016. Para isso, apurou-se entre os gestores, a visão das mudanças ocorridas nas organizações vencedoras em relação a estratégia, desempenho, clientes, concorrentes, fornecedores, parceiros e colaboradores, e buscou-se aferir em que medida são advindas da premiação. Tal prêmio foi escolhido em função de ser o principal, dedicado a essa temática no Brasil, aliado ao fato de que a premiação é a primeira no mundo a ser chancelada pela Organização Mundial do Turismo/ONU. A premiação é anualmente organizada pela Associação Brasileira das Operadoras de Turismo, conhecida como Braztoa - uma associação civil de direito privado, sem fins lucrativos, criada em 1989. A Associação engloba as operadoras de turismo descritas como empresas especializadas na prestação de serviços de operação de viagens; empresas de representação de destinos e serviços turísticos do exterior; colaboradores, isto é, empresas que promovem e/ou comercializam produtos e/ou serviços turísticos; e associados convidados, que, por sua vez, são empresas de diferentes segmentos que contribuem, de maneira direta ou indireta, para a cadeia produtiva do setor turístico. Um dos objetivos da Braztoa é auxiliar seus associados para que promovam práticas sustentáveis no turismo, com aspectos sociais, econômicos e ambientais (BRAZTOA, 2017).

No Programa de Sustentabilidade da instituição, insere-se o Prêmio Braztoa de Sustentabilidade, criado em 2012 para fortalecer, reconhecer e divulgar práticas das organizações associadas. Nas cinco edições da premiação, foram mais de duzentos projetos inscritos e mais de sessenta vencedores. As categorias mais recentes, estabelecidas para o Prêmio Braztoa de Sustentabilidade, são: Top Sustentabilidade, associados Braztoa, agências de viagem, meios de hospedagem, parceiros do turismo e projetos inovadores. O Prêmio, apoiado pelo Ministério do Turismo, assim como por outros parceiros, tem como objetivos: (1) Estimular a cadeia do turismo a 
agir de maneira ambientalmente responsável, socialmente justa e economicamente viável; (2) Incentivar o trade a oferecer produtos e serviços sustentáveis e possibilitar que as boas iniciativas sejam multiplicadas; (3) Fomentar a cultura empresarial de Gestão da Sustentabilidade no setor do turismo; (4) Reconhecer as melhores práticas e dar visibilidade às empresas e suas ações sustentáveis; e (5) Contribuir com a promoção do desenvolvimento sustentável do destino Brasil. Segundo a Braztoa (2017), o sistema de avaliação é baseado em quatro critérios: impactos ambientais, socioculturais e econômicos; incentivo ao turismo sustentável; viabilidade financeira; e abrangência e replicabilidade.

Uma análise do Prêmio, ano a ano, revela que houve ampliação do número de inscritos, desde a criação, com o recorde de inscritos em 2015. Quanto aos vencedores, foco deste trabalho, totalizaram 13 no ano de 2012; 15 a cada ano no período de 2013 a 2015; e cinco em $2016^{4}$. Ou seja, 63 organizações, que formam o grupo de interesse desta pesquisa. Entre as iniciativas premiadas durante anos, podem ser citados alguns exemplos, o turismo em parceria com a comunidade local como estratégia de desenvolvimento sustentável na região do Vale do Pati (Parque Nacional da Chapada Diamantina/BA). Há também o projeto Praia sem barreiras, promovido pela Secretaria de Turismo de Pernambuco, que tem como objetivo proporcionar autonomia e segurança para moradores e turistas com algum tipo de deficiência ou mobilidade reduzida, oferecendo o banho de mar assistido. Outra iniciativa, criada pela entidade Costa dos Corais Convention \& Visitors Bureau, em Alagoas, busca garantir a conservação dos corais, por uma lógica socioambiental e educativa. Ainda vale mencionar a Pousada Flutuante Uacari, premiada por utilizar diversas tecnologias com baixo impacto ambiental, como o uso de sistemas de trilhas, separador e clorador de água da chuva e máquina de gelo solar, com a comunidade local ativa em todo o processo de gestão da pousada e do entorno. Ademais, na cidade de Jaraguá do Sul/SC, uma iniciativa de implantar a geração de energia solar fotovoltaica e a captação de água da chuva também consta entre as vencedoras.

Com base no objetivo do estudo, a estrutura do artigo foi organizada de modo que, após esta introdução, apresenta-se o referencial teórico estruturado ao redor dos conceitos de sustentabilidade e responsabilidade no turismo, e das premiações para a sustentabilidade. Então, são apresentados os aspectos metodológicos da pesquisa, seguidos de resultados e discussão, e as considerações finais.

\section{Referencial teórico}

\subsection{Turismo, sustentabilidade e responsabilidade socioambiental corporativa (RSC)}

\footnotetext{
${ }^{4}$ Ano em que o número de ganhadores por categoria foi reduzido de três para um; assim, contou com um total de cinco vencedores.
} 
Sustentabilidade e responsabilidade socioambiental são termos que têm encontrado eco no universo corporativo e no setor de turismo. Sustentabilidade não é um termo somente técnico, mas também normativo e ocupa o status de carro-chefe da institucionalização da questão ambiental (NOBRE; AMAZONAS, 2002). O termo foi cunhado na década de 1970 e traz o reconhecimento de que existem externalidades da produção que podem ocorrer em diversas escalas, levando à compreensão de que são necessárias escolhas e decisões no presente que restrinjam o uso de recursos em nome de um futuro viável (DALY, 1999, 2004; BURSZTYN, 1995).

Isso leva à cobertura de diversos assuntos que permeiam o desenvolvimento assentado no tripé da sustentabilidade, ou Triple Bottom Line, que expressa a coexistência de aspectos ambientais, sociais e econômicos no desenvolvimento em longo prazo (SACHS, 2004; MENEZES et al., 2016). Para pensar-se em sustentabilidade, as três dimensões citadas devem estar conectadas e em constante tentativa para serem equilibradas, em um processo contínuo, sempre em construção e complexo (NASCIMENTO e COSTA, 2010).

A responsabilidade socioambiental corporativa (RSC), por sua vez, está diretamente relacionada com o conceito de sustentabilidade porque diz respeito a um conjunto de comportamentos voluntários das empresas que demonstram compromissos com questões ligadas ao tripé da sustentabilidade (ASHLEY, 2005; BERNARDES, 2006; BITTENCOURT e CARRIERI, 2005; BUFONI, MUNIZ e FERREIRA, 2009).

Para o turismo, a sustentabilidade apresenta-se como um desafio central, tanto pela dependência dos recursos naturais e culturais, quanto por conta dos impactos em milhões de pessoas que vivem nos destinos turísticos (LAGES, 2018). Swarbrooke (2000) afirma que o turismo não pode ser analisado à parte do contexto do desenvolvimento sustentável — um sistema considerado aberto em que tudo e todos são afetados, em virtude de estar relacionado não apenas com o ambiente físico, mas também com os ambientes cultural, social e econômico. Por conseguinte, com o desenvolvimento de formas mais sustentáveis de turismo, há a reprodução de seus efeitos nos elementos não turísticos do sistema. Portanto o turismo sustentável pode ser conceituado como o "atendimento das necessidades dos turistas de hoje e das comunidades receptoras, ao mesmo tempo em que protege e amplia as oportunidades para o futuro [...]" (OMT, 2003).

Rabinovici (2009) afirma que os impactos, nas localidades onde ocorre o turismo, têm tanto potencial desestruturador, quanto estruturador, com relação à comunidade. Dessa forma, para que as práticas relacionadas com o turismo sustentável sejam desempenhadas com eficácia e com 
MUDANÇAS OBSERVADAS EM

ORGANIZAÇÕES VENCEDORAS DO PRÊMIO

BRAZTOA DE SUSTENTABILIDADE EM

TURISMO
Luanna Suellen Lourdes dos Santos

Helena Araújo Costa

Solange Alfinito

possibilidade de alcançar um nível nacional, governos, como o brasileiro, têm criado programas e políticas públicas em conjunto com ONGs ambientalistas, transnacionais e nacionais. Para que o turismo sustentável seja possível, necessita-se de contribuições para o crescimento da economia por parte do turismo, da prudência no uso dos recursos naturais disponíveis, além de contribuir para uma equidade social, ou seja, ser guiado pelas premissas da sustentabilidade. Essas premissas são: a garantia da equidade, incluindo aspectos de participação social e redução da pobreza; a manutenção da qualidade e da disponibilidade de recursos naturais, levando-se em consideração os aspectos físico, social e cultural dos indivíduos e dos ambientes; a preservação da biodiversidade, evitando-se mudanças ambientais irreversíveis; a garantia de qualidade da experiência turística; e o encorajamento de estruturas locais de governança (NASCIMENTO e COSTA, 2018; COSTA, 2013).

Contudo existem críticas que permeiam o turismo sustentável, como a de Butler (1999). Do ponto de vista do autor, há uma tendência errônea de julgar as modalidades do turismo com base no conceito de desenvolvimento sustentável, em razão do pressuposto de que, quando elas são classificadas como "convencionais" ou de "massa", não são sustentáveis. E, quando são postas como "alternativas" ou "verdes", estão de acordo com os princípios sustentáveis. Butler (1999) aponta que é impossível ter uma modalidade que não tenha algum impacto no destino turístico, pois, mesmo sendo consideradas "verdes", as atividades podem ocasionar pequenos impactos que, individualmente, não causam problemas, mas, quando acumulados, tornam-se nocivos ao meio ambiente e à sociedade.

Partindo-se para o aprofundamento do entendimento sobre a RSC, o histórico de conceitos caracteriza-se por certa imprecisão (SERPA e FORNEAU, 2007), e perpassa uma multiplicidade de compreensões acerca das razões para as empresas adotarem tais comportamentos, desde um foco racional/econômico, em que as empresas buscam maximizar seus ganhos, quanto por questões focadas em crenças, valores e éticas dos indivíduos à frente dos negócios (COSTA et al., 2018; SOUZA e COSTA, 2013). Conforme Tenório et al. (2006), os elementos necessários para que organizações se motivem na implementação de uma gestão que norteie os fundamentos da RSC, são: pressões externas, forma instrumental ou questão de princípios. O primeiro elemento é atribuído às legislações ambientais, ao comportamento de compra dos consumidores, por pressão de comunidades locais afetadas pela atividade empresarial, aos sindicatos e, não menos importante, por organismos internacionais. O segundo elemento é atribuído a uma lógica instrumental, por meio do ganho de algum benefício, como o incentivo fiscal concedido pelo governo ou pela vantagem por parte da organização, como o aumento da preferência do consumidor pelos produtos e/ou serviços. No terceiro elemento, os valores das organizações que norteiam as práticas e políticas relacionadas com a 
MUDANÇAS OBSERVADAS EM

ORGANIZAÇÕES VENCEDORAS DO PRÊMIO

BRAZTOA DE SUSTENTABILIDADE EM

TURISMO
Luanna Suellen Lourdes dos Santos

Helena Araújo Costa

Solange Alfinito

responsabilidade socioambiental são incorporados no comportamento do mercado por meio da cultura organizacional e do relacionamento com stakeholders.

Para melhor compreensão, Serpa e Forneau (2007) destacaram as duas abordagens principais da responsabilidade social corporativa. A primeira é a econômica clássica, defendida por Friedman (1970), por declarar que uma organização socialmente responsável busca a maximização dos lucros. Já na abordagem socioeconômica, declara-se que, além da obtenção de lucros corporativos e geração de empregos, a organização promove o bem-estar social. Assim, à medida que a organização proporciona uma melhora nas condições de vida dos colaboradores, cumpre com a responsabilidade socioambiental (SERPA e FORNEAU, 2007). Todavia, nas duas abordagens, considera-se a sobrevivência da organização, o fator---chave para a garantia do atendimento dos interesses de acionistas e funcionários. Por consequência, é o requisito necessário para pensar-se no investimento em atividades que beneficiem outros stakeholders (SERPA e FORNEAU, 2007).

De acordo com Reis (2007), a propagação da noção da RSC é lenta, além de ter cargas histórica, filantrópica e assistencialista. Em vista disso, as reflexões sobre o tema ainda estão longe de encontrar consenso (LENZIARDI et al., 2010; REIS, 2007; SERPA e FORNEAU, 2007; AMORIM e CUSTÓDIO, 2010). A busca pela superação das expectativas dos atores sociais cria uma relação baseada em um contrato social, e é dessa forma que a sociedade legitima a existência da empresa, atestando suas atividades produtivas e obrigações, e limitando sua atuação no mercado. Assim, quando houver mudanças no contrato social entre a sociedade e os negócios, será inevitável considerar novas responsabilidades para conseguir-se corresponder às demandas existentes (BERTONCELLO e CHANG JÚNIOR, 2007).

No contexto brasileiro, Costa et al. (2018) evidenciaram que as medidas responsáveis mais implementadas pelas empresas de turismo são as de cunho ambiental, principalmente, ligadas à economia de energia ou água. Entre as práticas sociais identificadas, destacaram-se ações de preservação da cultura e do patrimônio locais, e a promoção da igualdade de gênero. Na dimensão econômica, a prática mais recorrente diz respeito à contratação de pessoas moradoras nas proximidades da empresa. Entre os motivos para a adoção dessas medidas, os autores evidenciaram a existência de dois grupos principais, sendo maior e mais expressivo o grupo que realiza ações de responsabilidade por conta de razões individuais - tais como, valores, ética e modo de vida - mais do que por razões ligadas ao desempenho econômico--financeiro de suas empresas. Ainda, o estudo revela que, os grupos não apresentam resultados financeiros diferentes, quando consideradas suas motivações para serem responsáveis. 
Além do mais, existem autores que constatam que os processos de escolha do consumidor para um determinado produto e/ou serviço serão favoráveis às organizações que focam seus esforços em favor da sustentabilidade e em implementações de práticas relacionadas com a responsabilidade socioambiental corporativa (RSC) (BHATTACHARYA, 2004; SEN, 2004; FERREIRA et al., 2010). Esse fato ocorreria em diversos setores, inclusive em relação ao setor turístico, como destacado pela obra de Lenziardi et al. (2010). Uma das principais razões para adotar-se compromisso com ações de RSC, no universo da hotelaria, estaria ligada ao aumento da lealdade dos turistas, explicada pelos níveis de confiança em tais empresas, pelo nível de identificação com elas e pelo grau de satisfação proporcionado (MARTINEZ e DEL BOSQUE, 2018). Em contrapartida, há autores que afirmam que as ações de RSC — por parte das organizações — gerariam interesse e impacto apenas para um número limitado de clientes, não necessariamente ocasionando a expansão da quantidade deles (KARLSSON e DOLNICAR, 2015). Ainda, há indícios de que, apesar de as organizações promoverem suas ações relacionadas com a RSC, elas trazem consigo certo ceticismo por parte dos consumidores que afirmam serem somente táticas de venda, pois elas podem ser vistas como oportunistas e superficiais (FONT et al., 2016). Consequentemente, essa percepção não exerceria muita influência na decisão de compra pelo consumidor (MOHR et al., 2001). Isso fica problematizado na abordagem de Serpa e Forneau (2007), quando indicam a importância de uma terceira parte isenta para mediar essa confiabilidade, o que poderia ser visto como um papel exercido pelas ecolabels e pelas premiações.

\subsection{Premiações para a sustentabilidade no turismo}

Os prêmios ligados à sustentabilidade, assim como outros mecanismos de ecolabels, tendem a influenciar produtores a oferecerem produtos ambientalmente mais responsáveis, e a promover uma comunicação mais clara e confiável com o mercado-alvo (VILLARINO e FONT, 2015; COSTA, 2013). De forma geral, as premiações em sustentabilidade podem influenciar os produtores ou os consumidores, o processo produtivo ou o produto em si mesmo (FONT et al., 2016; JORDAN et al., 2006) a avançar na temática. Os prêmios podem apontar liderança e exemplos a serem seguidos pelo setor (KOZAK e NIELD, 2004; FONT e TRIBE, 2001), e têm, como principal motivador, o reconhecimento social que oferecem aos vencedores (AYUSO, 2007).

No campo do turismo, Goodwin (2011) declara que, por meio dessas premiações, se consegue uma contribuição para a divulgação da mensagem sobre o turismo responsável, que, por sua vez, trata 
da responsabilidade assumida pelas organizações para tornar o turismo mais sustentável, com abordagens econômica, social e ambiental. Segundo o autor, a premiação não é um esquema para o credenciamento, muito menos está relacionada com certificações, mas com ela é possível achar ações dignas de serem notadas e difundidas. Os prêmios ligados à sustentabilidade podem ajudar o turista a identificar produtos mais benignos ao meio ambiente, e a encorajar maior atenção ao tema por parte dos provedores no mercado (FONT e TRIBE, 2001).

Em um contexto internacional, em 2003, foi criado pela Organização Mundial do Turismo um dos prêmios mais importantes no cenário do turismo mundial - o UNWTO Awards for Excellence and Inovation in Tourism, que, nas últimas edições, foi realizado em parceria com a Feira Internacional de Turismo de Madri. A premiação tem por fim o reconhecimento de projetos inovadores para um turismo mais sustentável baseados no Código Global de Ética para o Turismo da OMT (OMT, 2018). No mesmo ano, a National Geographic Society criou o World Legacy Awards, realizado em colaboração com a ITB Berlin. A premiação visa homenagear organizações visionárias quanto ao desenvolvimento de práticas sustentáveis no setor de turismo (NATIONAL GEOGRAPHIC, 2018). Já, em 2004, a Responsible Travel, uma operadora inglesa, foi a responsável pela criação do World Responsible Tourism Awards, realizado em colaboração com a feira World Travel Market, em Londres, que tem como objetivo principal realizar uma premiação confiável, destacar as iniciativas verdadeiramente relevantes no turismo responsável mundial, e, assim, torná-las inspirações para outras organizações. Uma vez que as práticas premiadas ganharam visibilidade, houve a criação de outras premiações em diversos países, com os mesmos parâmetros (RESPONSIBLE TRAVEL, 2018). Outro prêmio mundialmente reconhecido é Tourism for Tomorrow Awards, criado pelo World Travel \& Tourism Council, em 2004, que premia iniciativas para o turismo sustentável, fundamentadas nos seguintes princípios: operações ecologicamente corretas; apoio à proteção dos patrimônios cultural e natural; e benefícios diretos para o bem-estar socioeconômico da população local em destinos de viagem ao redor do mundo (WTTC, 2018).

Em seu sentido mais amplo, a ecolabel contém as informações pertinentes e de fácil compreensão sobre o produto e/ou serviço, como o desempenho ambiental da organização. Conforme esclarece Ayuso (2007), os principais incentivos para adotar tais instrumentos são: ganhos financeiros, respostas à demanda, considerações éticas e melhoria de imagem. Porém isso deve ser relativizado ao redor das diferentes motivações e ganhos para as empresas com base em diferentes instrumentos voluntários que podem ser adotados. Sasidharan et al. (2002) complementam a discussão, indicando que a implementação dos rótulos ecológicos traz benefícios para o setor do turismo: 
- Incentivo para que as organizações atinjam os padrões ambientais baseados nas regulamentações;

- Melhoria no desempenho ambiental e nas práticas ligadas ao meio ambiente;

- Disseminação de informações, entre os turistas, sobre os impactos dos produtos e/ou serviços turísticos;

- Certificação da solidez ambiental dos destinos turísticos;

- Ferramenta estratégica com relação aos benefícios ambientais.

Especificamente em relação aos prêmios em turismo, Font e Tribe (2001) contribuem ao analisarem e compararem 16 prêmios, possibilitando identificar pontos fortes e fracos deles para, então, sugerirem que é preciso uma atuação mais racional do setor, internacionalizando prêmios e rótulos ambientais. Os autores também identificam alguns fatores que influenciam uma empresa a inscrever-se para um prêmio: ser um requisito para algumas transações; perceber uma vantagem competitiva sobre seus competidores (até mesmo para organizações que não buscam lucro, pode ser relevante do ponto de vista da imagem, já que prêmios são dados a organizações com desempenhos superiores); e entrar no trâmite por ser menor do que os ganhos esperados.

Por meio das ecolabels, as organizações do turismo podem disseminar suas "credenciais ambientais"; o que pode proporcionar uma vantagem competitiva para a organização; incentivar a organização a manter e melhorar seus padrões de desempenho ambiental; ampliar a educação de seus mercados e auxiliar na comercialização de seus produtos e/ou serviços a um preço mais elevado, uma vez que são considerados "ambientalmente amigáveis" (SASIDHARAN et al., 2002). Ademais, os próprios turistas podem ser beneficiados pelos rótulos ecológicos, já que obtêm maiores informações que podem interferir no processo de escolha entre provedores alternativos (BUCKLEY, 2002; FONT et al., 2016).

Existe, portanto, uma expectativa de que os turistas valorizem as ecolabels e, consequentemente, desenvolvam atitudes positivas relacionadas com os produtos e/ou serviços da organização certificadas e/ou premiadas (SASIDHARAN et al., 2002). Todavia ainda permanece indefinido de que forma uma premiação afeta a compra e a escolha por parte do turista (BUCKLEY, 2002). Achados de outros estudos enfatizam que nem todo o mercado turístico é persuadido por essas mensagens, mas sim um nicho previamente sensível a elas (KARLSSON e DOLNICAR, 2015; PAN et al., 2018). 
MUDANÇAS OBSERVADAS EM

ORGANIZAÇÕES VENCEDORAS DO PRÊMIO

BRAZTOA DE SUSTENTABILIDADE EM

TURISMO
Luanna Suellen Lourdes dos Santos

Helena Araújo Costa

Solange Alfinito

Ayuso (2007) aponta que, apesar de a premiação possibilitar uma melhoria de comunicação com os clientes, isso pode ser acompanhado ou não de um aumento de vendas. Portanto o benefício econômico da conversão em vendas é tido mais como uma possibilidade do que como uma certeza com base na consecução de uma ecolabel. Fica então configurado que as premiações tendem a apresentar mais benefícios potenciais do ponto de vista de reconhecimento, comunicação, reputação e gestão empresarial e de destinos (FONT e TRIBE, 2001; BUCKLEY, 2002; KOZAK e NIELD, 2004; AYUSO, 2007) do que, necessariamente, do ponto de vista econômico.

\section{Metodologia}

A pesquisa teve abordagem quantitativa e foi realizada por meio de survey, ou seja, um levantamento de campo cuja característica é a interrogação de forma direta ao grupo de indivíduos estudado em que se deseja conhecer o comportamento (GIL, 2008). A aplicação do questionário estruturado foi realizada por meio de plataforma on-line, por trinta dias consecutivos, entre setembro e outubro de 2017, com o apoio da Braztoa para a divulgação do instrumento entre os premiados, uma vez que a associação teve participação ativa tanto na elaboração das perguntas, quanto no envio de $e$ mail que motivasse as organizações premiadas a responderem ao questionário.

A população considerada foi das 63 organizações premiadas durante cinco edições do Prêmio Braztoa de Sustentabilidade, de 2012 a 2016, contabilizadas em base de dados elaborada pela Braztoa, que alimenta o "Mapa de Turismo Sustentável no Brasil: Iniciativas Premiadas", disponível no site do Ministério do Turismo. Obteve-se uma taxa de resposta de 35\%, alcançando-se 22 das organizações premiadas entre 2012 e 2016. Os respondentes, em sua maioria, foram indivíduos com cargos gerenciais nas empresas vencedoras. A predominância desse nível hierárquico deve-se ao fato de que os funcionários têm habilidade de tomar decisões de acordo com as necessidades da organização e do ambiente externo (SANTOS, 2011). Assim, têm a capacidade de identificar as mudanças geradas na organização após ser vencedora do Prêmio Braztoa de Sustentabilidade.

O instrumento consistiu em um questionário estruturado com 37 perguntas divididas em quatro seções. Na seção 1, abordaram-se características da ação premiada e da situação atual. Na seção 2, constituída de 21 itens, em escala Likert clássica de concordância, perguntou-se acerca de possíveis mudanças observadas na organização desde que a ação foi premiada, variando de 1 a 5 (1=discordo totalmente, e 5=concordo totalmente). Na seção 3, composta de três questões categóricas ("sim", "não" e "não sei") e de seis questões abertas, para identificar expectativas e sentimentos do respondente com relação ao prêmio. A última pergunta da seção, estruturada em uma escala de 
MUDANÇAS OBSERVADAS EM

ORGANIZAÇÕES VENCEDORAS DO PRÊMIO

BRAZTOA DE SUSTENTABILIDADE EM

TURISMO
Luanna Suellen Lourdes dos Santos

Helena Araújo Costa

Solange Alfinito

classificação de 0 a 10, foi feita com o intuito de, após averiguarem-se as possíveis mudanças percebidas na organização, ser possível medir o quanto os respondentes atribuíam as mudanças ao prêmio recebido, já que não se podia inferir que todas as mudanças eram resultantes apenas do prêmio em questão. Desse modo, estabelecer uma relação direta de causa e efeito não seria apropriado. Por fim, na última seção, abordaram-se dados que caracterizassem a empresa, tais como atividade principal, porte, localização e cargo do respondente.

A análise de dados foi dividida em duas fases: análise estatística descritiva, para melhor compreensão da iniciativa premiada, da premiação e do perfil das empresas/organizações); e análise estatística inferencial, com a condução de correlações não paramétricas de Kendall-Tau.

\section{Resultados e discussão}

Esta seção está organizada em dois tópicos: no primeiro, descreve-se a situação atual das iniciativas premiadas e suas organizações, no que diz respeito à relação com a premiação e as características das organizações; no segundo, abordam-se as mudanças percebidas após a premiação, e as influências do Prêmio Braztoa para tais mudanças.

\subsection{Situação atual das iniciativas premiadas e suas organizações}

A fim de caracterizar as organizações premiadas respondentes da pesquisa e o status das iniciativas, verificou-se que as atividades principais da maioria das organizações participantes da pesquisa são de hotelaria $(\mathrm{N}=7)$, seguidas por agência de viagens $(\mathrm{N}=4)$ e operadoras de turismo $(\mathrm{N}=3)$. Entretanto elas são, na maioria de pequeno porte (de dez a 49 funcionários) $(\mathrm{N}=11)$ ou de microporte (até nove funcionários) $(\mathrm{N}=6)$. Ainda, quanto à localização das organizações participantes, metade ( $\mathrm{N}=11)$ está localizada na região sudeste do Brasil e oito, na região sul. Pode-se afirmar que o maior número de empresas respondentes foram ganhadoras, em 2016 com 36,4\% (N=8). O total de empresas que ganhou apenas uma vez é de $86,3 \%(\mathrm{~N}=19)$. É predominante a visão dos respondentes $(54,5 \%)$ de que a ação premiada foi aprimorada. E 40,9\% (N=9) dos respondentes afirmaram que a ação premiada ainda é mantida nos mesmos moldes de quando foi premiada, sem aprimoramentos ou reduções. Portanto se demonstra que a maioria expressiva das empresas premiadas deu continuidade às ações premiadas ou até mesmo as aprimorou após a premiação. Entre tais ações, encontram-se: gestão voltada para a sustentabilidade e turismo; reciclagem, reutilização de resíduos sólidos e/ou tratamento de água/esgoto; educação ambiental; ações sociais; recuperação e/ou conservação da fauna e flora; 
valorização da cultura local; inclusão social; desenvolvimento econômico; capacitação e desenvolvimento profissional; e utilização de energia sustentável.

Isso indica que o prêmio alcança um de seus objetivos propostos no que diz respeito a incentivar o trade a oferecer produtos e serviços sustentáveis e possibilitar que as iniciativas sejam multiplicadas. Além do mais, reafirma a convicção de que o tripé da sustentabilidade está presente na estratégia organizacional dessas empresas que buscam um turismo mais responsável (MENEZES et al., 2016). No entanto um dos respondentes afirmou que a ação premiada, referente à educação ambiental, foi reduzida. Esse caso merece uma verificação futura mais pontual a fim de compreender as razões que podem explicar tal comportamento.

Ademais, nota-se que $77,3 \%(\mathrm{~N}=17)$ das empresas/organizações foram premiadas na primeira participação no Prêmio Braztoa de Sustentabilidade. Entretanto a maioria das empresas foi premiada somente uma vez pelo Prêmio Braztoa na primeira participação, o que demonstra que os novos participantes têm obtido sucesso na premiação. Além disso, denota que a premiação, nas edições, tem tido adesão de novos participantes.

Conforme verificado, $63,6 \%(\mathrm{~N}=14)$ das organizações respondentes voltaram a inscrever-se no Prêmio após serem premiadas, o que apresenta uma expressiva e importante reincidência. E 68,2\% $(\mathrm{N}=15)$ dos respondentes expressaram interesse em voltar a inscrever-se na premiação - dois relataram que, talvez, se inscrevessem na premiação novamente e apenas dois afirmaram que não voltariam a inscrever-se no Prêmio. Observa-se que a quantidade de respondentes que voltaram a inscrever-se é semelhante ao número de respondentes que expressaram interesse em inscrever-se nova e majoritariamente, sinalizando um nível positivo de satisfação com o prêmio.

Com relação a outros prêmios recebidos, algumas das organizações respondentes já foram premiadas. Assim, 40,9\% (N=9) já receberam outras premiações de sustentabilidade, mas a maioria $(\mathrm{N}=11)$ afirmou não ter recebido nenhuma premiação além do Prêmio Braztoa de Sustentabilidade.

\subsection{Mudanças observadas no período e a influência do Prêmio Braztoa de Sustentabilidade}

Quando perguntados acerca das mudanças observadas na organização desde a premiação, os respondentes atribuíram-se notas, expressas na Tabela 1. 
Tabela 1. Média, moda e desvio padrão das mudanças investigadas

\begin{tabular}{l|c|c|c}
\hline \multicolumn{1}{c|}{ Aspecto investigado } & Média & Moda & $\begin{array}{c}\text { Desvio } \\
\text { padrão }\end{array}$ \\
\hline $\begin{array}{l}\text { Passou a ofertar produtos/serviços comprometidos com a } \\
\text { sustentabilidade }\end{array}$ & 4,273 & 5 & 1,077 \\
\hline Aumentou o compromisso com a questão da sustentabilidade & 4,273 & 5 & 1,202 \\
\hline Inseriu a sustentabilidade no planejamento de longo prazo & 4,182 & 5 & 1,140 \\
\hline Aumentou a qualidade dos produtos/serviços & 4,091 & 4 & 1,151 \\
\hline $\begin{array}{l}\text { Aprimorou a cultura interna de gestão voltada para } \\
\text { sustentabilidade }\end{array}$ & 4,045 & 4 & 0,999 \\
\hline $\begin{array}{l}\text { Repassou conhecimento sobre a iniciativa para outras } \\
\text { organizações }\end{array}$ & 4,045 & 5 & 1,174 \\
\hline $\begin{array}{l}\text { Tornou-se mais conhecida do público-alvo (mídia convencional e } \\
\text { espontânea) }\end{array}$ & 4 & 4 & 0,976 \\
\hline Diminuiu impactos negativos sobre o meio ambiente & 4 & 5 & 1,195 \\
\hline $\begin{array}{l}\text { Encorajou o envolvimento dos funcionários com questões de } \\
\text { sustentabilidade }\end{array}$ & 4 & 5 & 1,272 \\
\hline Fortaleceu parcerias para ações de sustentabilidade & 3,955 & 5 & 1,046 \\
\hline Fortaleceu ações de sustentabilidade & 3,955 & 5 & 1,214 \\
\hline $\begin{array}{l}\text { Diferenciou-se mais claramente da concorrência pelas questões de } \\
\text { sustentabilidade }\end{array}$ & 3,909 & 4 & 1,019 \\
\hline Envolveu mais a comunidade nas atividades & 3,818 & 4 & 1,296 \\
\hline $\begin{array}{l}\text { Passou a exigir comportamentos mais sustentáveis de } \\
\text { fornecedores }\end{array}$ & 3,5 & 3 & 1,263 \\
\hline $\begin{array}{l}\text { Aumentou o número de clientes } \\
\text { Aumentou clientes que voltaram a comprar produtos/serviços }\end{array}$ & 3,318 & 4 & 1,427 \\
\hline Aumentou investimentos & 3,182 & 4 & 1,259 \\
\hline Fortaleceu relações entre empresa e fornecedores & 4,045 & 3 & 1,259 \\
\hline $\begin{array}{l}\text { Melhorou resultados econômicos da empresa } \\
\text { Aumentou faturamento (receita bruta) }\end{array}$ & 3,818 & 1,220 \\
\hline
\end{tabular}

Fonte: Dados da pesquisa.

Os resultados da Tabela 1 sinalizam que foram percebidas mudanças positivas na organização, que podem ter contribuído para a manutenção e o aprimoramento da iniciativa premiada pela maior parte dos respondentes, destacando-se as que mostram médias nos pontos mais altos da escala (iguais ou maiores que quatro e iguais a quatro ou cinco). Elas dizem respeito, de modo mais geral, a um maior engajamento com a questão da sustentabilidade, quer seja na oferta de produtos/serviços, no compromisso com o tema em longo prazo e na cultura organizacional, no repasse de conhecimento para outras organizações, e na própria minimização dos impactos ambientais negativos.

Esses tópicos remetem à abordagem socioeconômica de RCS, apresentada por Serpa e Forneau (2007), pois para atender a todos os stakeholders, e, por consequência, promover o bem-estar social, as ações indicam estar baseadas na sustentabilidade desde o planejamento estratégico até o oferecimento de produtos e/ou serviços de alta qualidade para a sociedade. De modo análogo a Tenório et al. (2007), os resultados da Tabela 1 também mostram indícios de que a implementação de uma gestão voltada 
para os fundamentos da responsabilidade socioambiental nas empresas é incorporada na estratégia e no desempenho perante o mercado, e no relacionamento com os stakeholders, tais como concorrentes, funcionários e clientes.

Por outro lado, as mudanças com menores graus de concordância foram referentes aos resultados econômicos no período analisado. A única mudança que ocupou o extremo inferior da escala, com média abaixo de três, diz respeito ao aumento do faturamento, indicando que as vencedoras tenderam a discordar dessa afirmativa. Esse tema deve ser tratado com cautela, pois diversos outros fatores podem ter contribuído para isso, tal como a conjuntura econômica de crise econômica nos últimos anos. Quando problematizada a questão do retorno financeiro em relação às práticas de RSC, Costa et al. (2018) já indicaram que, apesar de ser o viés mais presente na literatura, no turismo brasileiro evidenciou-se que o foco nos negócios não consistia na motivação predominante para a adoção de práticas ligadas à sustentabilidade.

Para aprofundar o entendimento do impacto da premiação para a organização, do ponto de vista dos respondentes, considerando-se as limitações da análise descritiva anterior, foi verificado o grau de associação entre o quanto eles atribuíram a mudanças percebidas ao Prêmio Braztoa de Sustentabilidade e diversos possíveis benefícios esperados das premiações, conforme apresentado na Tabela 2, por meio de análise de correlação não paramétrica de Kendall-Tau.

Tabela 2. Impacto da premiação em relação a mudanças percebidas pelas organizações

\begin{tabular}{l|c}
\hline Aspectos avaliados & $\tau$ \\
\hline Aumentou o número de clientes & 0,723 \\
\hline Fortaleceu relações entre a empresa e os fornecedores & 0,624 \\
\hline Fortaleceu parcerias para ações de sustentabilidade & 0,602 \\
\hline Tornou-se mais conhecida do público-alvo (mídia convencional e espontânea) & 0,584 \\
\hline Fortaleceu ações de sustentabilidade & 0,543 \\
\hline Passou a ofertar produtos/serviços comprometidos com a sustentabilidade & 0,533 \\
\hline Envolveu mais a comunidade nas atividades & 0,477 \\
\hline Aumentou clientes que voltaram a comprar os produtos/serviços (fidelidade) & 0,473 \\
\hline Aumentou faturamento (receita bruta) & 0,470 \\
\hline Aumentou investimentos & 0,423 \\
\hline Encorajou o envolvimento dos funcionários com questões de sustentabilidade & 0,419 \\
\hline
\end{tabular}




\begin{tabular}{l|c}
\hline Repassou conhecimento sobre a iniciativa para outras organizações & 0,418 \\
\hline Melhorou os resultados econômicos da empresa & 0,412 \\
\hline Inseriu a sustentabilidade no planejamento de longo prazo & 0,412 \\
\hline Aumentou compromisso com a questão da sustentabilidade & 0,356 \\
\hline
\end{tabular}

Nota. $\tau=$ coeficiente de correlação de Kendall-Tau dos itens significativos $(p<0,05)$.

Fonte: Dados da pesquisa.

De acordo com a Tabela 2, ordenada do maior coeficiente de correlação $(\tau=0,723)$ para o menor $(\tau=0,356)$, constata-se que a maioria das mudanças investigadas está associada à premiação recebida, em razão das correlações serem significativas $(p<0,05)$. Dessas, seis são consideradas elevadas, com tamanho do efeito grande, acima de 0,50, de acordo com Cohen (1992). Portanto existe uma forte relação entre a ocorrência da premiação e, principalmente, os primeiros seis itens de mudanças avaliadas. Com base na análise desses itens, verifica-se que, conforme Sasidharan et al. (2002), a premiação trouxe de fato, benefícios para essas organizações, como o incentivo para manutenção e melhora dos padrões de desempenho ambiental por meio de um comprometimento ainda maior com uma gestão sustentável, além de dar auxílio na comercialização de produtos e/ou serviços e disseminar informações pertinentes para fornecedores, colaboradores, clientes e até concorrentes.

A mudança mais fortemente associada à premiação diz respeito ao aumento de clientes, que pode estar ligada também a outros dois itens avaliados: ter-se tornado mais conhecida do público-alvo; passar a ofertar produtos/serviços comprometidos com a sustentabilidade. As três mudanças percebidas indicam haver aumento da visibilidade para a organização vencedora. Isso corrobora a visão de que as premiações tendem a resultar mais em benefícios ligados a aspectos de imagem, comunicação e posicionamento (KOZAK e NIELD, 2004; FONT e TRIBE, 2001), do que a resultados econômicos-financeiros. Por outro lado, a alta correlação entre o aumento do número de clientes derivada da premiação nas organizações, pode ter sido resultante da atenção por parte de nichos de consumidores sensíveis ao tema, priorizando escolhas mais sustentáveis, como destacam Karlsson e Dolnicar (2015) e Pan et al. (2018), bem como por conta de ampliação da lealdade dos clientes, que, na perspectiva de Martinez e Del Bosque (2018), está atrelada a ações responsáveis das empresas. De qualquer forma, há indícios de um fortalecimento da organização em relação ao mercado-alvo.

Outras três mudanças percebidas e correlacionadas ao impacto da premiação foram: fortalecimento das relações entre a empresa e os fornecedores; fortalecimento de parcerias para ações de sustentabilidade; fortalecimento de ações de sustentabilidade. Esses itens também parecem permeados pela lógica da ação em favor da sustentabilidade, especialmente entre outros stakeholders, 
MUDANÇAS OBSERVADAS EM

ORGANIZAÇÕES VENCEDORAS DO PRÊMIO

BRAZTOA DE SUSTENTABILIDADE EM

TURISMO
Luanna Suellen Lourdes dos Santos

Helena Araújo Costa

Solange Alfinito

o que permite imputar ao prêmio impactos ligado a influências positivas no processo produtivo, bem como à ampliação da liderança, expressa por meio dos exemplos a serem seguidos no setor, o que ressalta aspectos vinculados ao reconhecimento social dos premiados. Esses aspectos corroboram a visão de Font e Tribe (2001), Goodwin (2011) e Auyso (2007), acerca de benefícios das premiações de sustentabilidade em turismo.

$\mathrm{Na}$ etapa seguinte do estudo, abriu-se para comentários dos respondentes em relação às mudanças geradas pela premiação na organização. Metade dos respondentes comentou de forma livre e surgiram as seguintes evidências: que a premiação trouxe um maior reconhecimento e respeito em nível nacional para a empresa; que houve maior engajamento da equipe quanto à manutenção de ações sustentáveis e na adoção de novos projetos voltados para a sustentabilidade, fortalecendo os achados na Tabela 2. Além disso, mencionou-se o aumento da credibilidade, um aspecto anteriormente citado por Font et al. (2016) como uma das razões para empresas participarem de certificações ou prêmios, evitando-se, assim, serem mal interpretadas como oportunistas por parte dos clientes, e terem o reconhecimento apontado por Ayuso (2007). Todavia um respondente afirmou que as mudanças ocorridas são em nível intermediário e que, em sua opinião, não foram decorrentes do prêmio.

Por fim, ganhos econômicos tendem a ser tratados mais como uma possibilidade, segundo Ayuso (2007), que também revela que esse aspecto não consiste no maior motivador para as empresas buscarem premiações, mas sim um reconhecimento social dos esforços, o que encontra respaldo nos resultados da pesquisa. Adicionalmente, os resultados reforçam que iniciativas, como o Prêmio Braztoa, divulgam a importância do turismo sustentável, como indicado por Goodwin (2011).

\section{Considerações finais}

Este artigo tem como objetivo analisar as mudanças observadas nas organizações vencedoras do Prêmio Braztoa de Sustentabilidade, de 2012 a 2016. Apura-se, então, a visão de gestores sobre a situação atual das iniciativas premiadas, as mudanças ocorridas em relação a estratégia, desempenho, clientes, concorrentes, fornecedores, parceiros e colaboradores, além da influência do Prêmio para tais mudanças. A pesquisa, baseada em um survey on-line aplicado em vencedores da premiação, tem os dados tratados quantitativa e agregadamente, por meio de estatísticas descritiva e inferencial, com foco em retratar as mudanças de gestão que ocorreram nas organizações após a premiação, e não as mudanças pontuais em cada ação vencedora.

Quanto à situação atual das iniciativas premiadas, apura-se que praticamente a totalidade das empresas aprimora ou mantém as iniciativas após a premiação, indicando que o prêmio cumpre com 
seu objetivo de incentivar o trade a oferecer produtos e/ou serviços sustentáveis e possibilitar que suas iniciativas sejam multiplicadas. Em relação às organizações vencedoras que participaram da pesquisa, a maioria das empresas foi premiada apenas uma vez pelo Prêmio Braztoa e, na primeira participação, o que demonstra que novos participantes têm obtido sucesso na premiação e que a premiação tem tido adesão de novos candidatos. Ressalta-se, ainda, que uma parcela significativa já foi premiada por outros prêmios, constatando-se que há uma consistência quanto às iniciativas sustentáveis das ganhadoras.

Foi possível identificar que as mudanças percebidas pelas vencedoras dizem mais respeito a aspectos estratégicos, de cultura interna e de planejamento, do que a aspectos ligados a vendas e retorno do faturamento. Com base na correlação significante entre as mudanças observadas e o impacto da premiação, revela-se que a maioria das mudanças investigadas é atribuída ao Prêmio. Ainda, foi possível identificar dois grupos de mudanças como mais relevantes: o primeiro ligado ao mercado consumidor (os clientes) e o segundo ligado a outros stakeholders (fornecedores, parceiros). No primeiro grupo, revelam-se aspectos ligados ao posicionamento, à imagem e à comunicação das organizações vencedoras no que tange à sustentabilidade. Já no segundo grupo englobam-se aspectos ligados à liderança exercida pelos vencedores, e ao reconhecimento pelo setor.

Ambos os grupos fortalecem a visão de que o Prêmio Braztoa de Sustentabilidade no Turismo contribuiu para o fortalecimento de premissas de sustentabilidade na atuação das organizações vencedoras em diferentes aspectos e níveis. Esses resultados indicam que o Prêmio avaliado alcança quatro dos cinco objetivos: estimular a cadeia do turismo a agir de maneira ambientalmente responsável, socialmente justa e economicamente viável; incentivar o trade a oferecer produtos e serviços sustentáveis e possibilitar que as boas iniciativas sejam multiplicadas; fomentar a cultura empresarial de Gestão da Sustentabilidade no setor do turismo; reconhecer as melhores práticas e dar visibilidade às empresas e suas ações sustentáveis.

As limitações identificadas no presente estudo dizem respeito à escassa literatura sobre o tema das premiações em sustentabilidade e aos ajustes necessários ao método para uma coleta de dados online, o que limitou o aprofundamento de alguns aspectos. Então, para estudos futuros, há possibilidade de aprofundarem-se as variáveis investigadas com verificações in loco e com dados qualitativos que permitam compreender casos específicos, bem como um estudo de abrangência internacional com outras premiações de sustentabilidade no turismo.

\section{Referências}


ALMEIDA, F. O bom negócio da sustentabilidade. Rio de Janeiro: Nova Fronteira, 2002.

ALMEIDA, F.; SOBRAL, F. Responsabilidade social das empresas: um estudo empírico sobre a atitude dos gestores brasileiros. Revista Portuguesa e Brasileira de Gestão, p. 52-61, 2007.

AMORIM, R. C. M.; CUSTÓDIO, L. S. A necessidade de estruturação dos pressupostos da sustentabilidade e da responsabilidade social empresarial para as realidades de ensino/aprendizagem nos cursos de administração. Revista Científica do Departamento de Ciências Jurídicas, Políticas e Gerenciais do Uni-BH, vol. 3, n. ${ }^{\circ}$ 1, 2010.

ARAÚJO, G. C.; BUENO, M. P.; SOUSA, A. A.; MENDONÇA, P. S. M. Sustentabilidade empresarial: conceitos e indicadores. In: CONVIBRA, 3., 2006. Anais... 2006.

ASHLEY, A. P. Ética e responsabilidade social nos negócios. São Paulo: Saraiva. 2005.

AYUSO, S. Comparing voluntary policy instruments for sustainable tourism: the experience of the Spanish Hotel Sector. Journal of Sustainable Tourism, vol. 15, n. ${ }^{\circ}$ 2, p. 144-159, 2007 (DOI: $10.2167 /$ jost617.0).

BACHA, M. L.; SANTOS, J.; SCHAUM, A. Considerações teóricas sobre o conceito de sustentabilidade. In: SIMPÓSIO DE EXCELÊNCIA EM GESTÃO E TECNOLOGIA, 7. Anais... 2010.

BARBIERI, J. C.; VASCONCELOS, I. F. G.; ANDREASSI, T.; VANCONCELOS, F. C. Inovação e sustentabilidade: novos modelos e proposições. Revista de Administração de Empresas. vol. 50, n. ${ }^{\circ} 2$, p. 140-154, São Paulo, 2010.

BARBOSA, M. L. A.; ZAIDAN, B. C. V. C.; RODD, M.; ANDRADE, M. B. Responsabilidade social, identidade de marca e rótulos ambientais: um estudo comparativo de empresas de serviços de hospedagem do Brasil e da Holanda. Revista de Turismo Contemporâneo RTC, Natal, vol. 5, n. ${ }^{\circ}$, p. 156-179, jul./dez. 2017.

BATISTA, I. H.; ALBUQUERQUE, C. C. Desenvolvimento sustentável: novos rumos para a humanidade. Revista Eletrônica Aboré. 3. ed, 2007.

BERNARDES, B. Q. T. Responsabilidade socioambiental das micro e pequenas empresas do DF. Mestrado (Desenvolvimento sustentável) pela Universidade de Brasília, Brasília. 2006.

BERTONCELLO, S. L. T.; CHANG JÚNIOR, J. A importância da responsabilidade social corporativa como fator de diferenciação. Revista da Faculdade de Comunicação da FAAP, n. ${ }^{\circ}$ 17, p. 70-76, 2007.

BITTENCOURT, E.; CARRIERI, A. D. P. Responsabilidade social: ideologia, poder e discurso na lógica empresarial. RAE, 45. 2005.

BRAZTOA. Disponível em: <http://braztoa.com.br/>. Acesso em: 3 jul. 2017.

BUCKLEY, R. Tourism ecolabels. Annals of Tourism Research. vol. 29, n. ${ }^{\circ}$ 1, p. 183-208, 2002.

BUFONI, A. L.; MUNIZ, N. P.; FERREIRA, A. C. D. S. O processo de certificação socioambiental das empresas: o estudo de caso do certificado 'Empresa Cidadã'. RAC, 13, p. 19-38, 2009.

BURSZTYN, M. Armadilhas do progresso: contradições entre economia e ecologia. Revista Sociedade e Estado, vol. 10, n. ${ }^{\circ} 1$, p.97-124, 1995. 
BUTLER, R. W. Sustainable tourism: a state-of-the-art review. Tourism geographies, p. 7-25, 1999. Disponível em: < http://www.tandfonline.com/doi/abs/10.1080/14616689908721291>. Acesso em: 14 jul. 2017.

CAMPOS, A. M. N. O ecoturismo como alternativa de desenvolvimento sustentável. Caderno Virtual de Turismo, vol. 5, n. ${ }^{\circ}$ 1, Rio de Janeiro, 2005.

CHEHADE, M. B.; SANTOS, R. A.; SANTOS, V. N. A. Turismo sustentável: a importância da atividade turística como forma de sensibilização. Revista Científica Eletrônica de Turismo, n. ${ }^{\circ} 10$, Garça/SP, 2009.

COHEN, J. A power primer. Psychological bulletin, vol. 112, n. ${ }^{\circ}$ 1, p. 155, 1992.

COSTA, H. A. Destinos do turismo: percursos para a sustentabilidade. Rio de Janeiro: FGV, 2013.

; FONT, X.; GARAY, L.; JONES, S. Foco nos negócios x foco nos indivíduos: razões para implementar práticas de responsabilidade empresarial no turismo brasileiro. Revista Turismo Visão e Ação, vol. 3, n. ${ }^{\circ}$ 20, p. 474-489, 2018.

DALY, H. Crescimento sustentável? Não, obrigado. Ambiente e Sociedade, vol.7, n. ${ }^{0}$ 2, 2004.

.Políticas para o desenvolvimento sustentável. In: CAVALCANTI, C. O. (Org.). Meio ambiente, desenvolvimento sustentável e políticas públicas, p.179-192, 1999.

FRIEDMAN, M. The social responsibility of business is to increase its profits. The New York Times Magazine, 1970.

FONT, X. Environmental certification in tourism and hospitality: progress, process and prospects. Annals of Tourism Research, p. 197-205, 2002.

.; ELGAMMAL L., I.; LAMOND, I. Greenhushing: the deliberate under communicating of sustainability practices by tourism businesses. Journal of Sustainable Tourism, 2016.

; TRIBE, J. Promoting green tourism: the future of environmental awards. International Journal of Tourism Research, p. 9-21, 2001.

GIL, A. C. Métodos e técnicas de pesquisa social. 6. ed. São Paulo: Atlas, 2008.

GOLDEN, Jay S. (Ed). An overview of ecolabels and sustainability certifications in the global marketplace. October 2010. Corporate Sustainability Initiative - Nicholas Institute for Environmental Policy Solutions - Duke University. Disponível em: <www.SustainabilityConsortium.org>. Acesso em: abr. 2018.

GOODWIN, H. The 2011 Virgin Holidays responsible tourism awards. Taking Responsibility for Tourism, vol. 1, p. 102-127, 2011.

JORDAN, A; WURZELl, R; ZITO, A; BRUCKNER, A. Consumer responsibility taking and ecolabeling schemes in Europe. Michele Micheletti, Dietlind Stolle, Andreas Follesdal. (Eds.). Politics, products, and markets: exploring political consumerism transaction. Publishers New Jersey, p. 161-180, 2006.

KARLSSON, L.; DOLNICAR, S. Does eco certification sell tourism services? Evidence from a quasiexperimental observation study in Iceland. Journal of Sustainable Tourism (DOI 10.1080/09669582.2015.1088859), 2015.

KOZAK, M.; NIELD, K. The role of quality and eco-labelling systems in destination benchmarking. Journal of Sustainable Tourism, vol.12, n. ${ }^{\circ}$ 2, p. 138-148, 2004. 
LAGES, V. Prefácio. In: NASCIMENTO, E. P. D.; COSTA, H. A. (Orgs.). Turismo e sustentabilidade: verso e reverso. Rio de Janeiro: Garamond, 2018, p. 7-17.

LENZIARDI, R.; MAYER, V. F.; FERREIRA, D. A. O turista se importa?: a responsabilidade social e a escolha de um meio de hospedagem. In: ENCONTRO DA ANPAD, 34. Anais... Rio de Janeiro/RJ: ANPAD, 2010.

MACHADO, V. F. A produção do discurso do desenvolvimento sustentável: de Estocolmo à Rio92. In: ENCONTRO DA ANPPAS, 3. Anais... Brasília/DF: ANPPAS, 2006.

MARTINEZ, P.; DEL BOSQUE, I. Determinación del papel de las características demográficas de los consumidores en el proceso de formación de lealtad basada en aspectos socialmente responsables. Cuadernos de Turismo, vol. 42, p. 317-333, 2018.

MENEZES, U. M.; GOMES, A. F.; DANTAS, M. Z. Sustentabilidade e seus benefícios: práticas e ações sustentáveis desenvolvidas em empresas do Distrito Industrial dos Imbóres. In: SEMAD, 18. Anais... vol. 3, n. ${ }^{\circ}$ 1. Vitória da Conquista/BA: SEMAD, 2016.

MINISTÉRIO DO TURISMO. Disponível em: <http://www.turismo.gov.br/>. Acesso em: 4 jul. 2017.

MOHR, L. A.; WEBB, D. J.; HARRIS, K. E. Do consumers expects companies to be socially responsible?: the impact of corporate social responsibility on buying behavior. The Journal of Consumer Affairs, vol. 35, n. ${ }^{\circ}$ 1, p. 45-72, 2001.

NASCIMENTO, E. P. D.; COSTA, H. A. Sustainability as a new political field. Au-delà du Développment/Beyond Development, vol. 4, p. 51-57, 2010.

. (Orgs.). Turismo e sustentabilidade: verso e reverso. Rio de Janeiro: Garamond, 2018.

NATIONAL GEOGRAPHIC. About the awards. Disponível em: < https://www.nationalgeographic.com/worldlegacyawards/about-the-awards.html>. Acesso em: 10 dez. 2018.

NOBRE, M.; AMAZONAS, M. D. C. Desenvolvimento sustentável: a institucionalização de um conceito. Brasília: IBAMA, 2002.

OLIVEIRA, L. R.; MEDEIROS, R. M.; TERRA, P. B.; QUELHAS, L. G. Sustentabilidade: da evolução dos conceitos à implementação como estratégia nas organizações. Revista Produção, vol. $22,{ }^{\circ}{ }^{\circ} 1$, p. $70-82,2012$.

ONUBR (NAÇÕES UNIDAS NO BRASIL). A ONU e o meio ambiente. Disponível em: < https://nacoesunidas.org/acao/meio-ambiente/>. Acesso em: 22 maio 2017.

PAN, S. Y.; GAO, M.; KIM, H.; SHAH, K. J.; PEI, S. L.; CHIANG, P. C. Advances and challenges in sustainable tourism toward a green economy. Science of the Total Environment, vol. 635, p. 452--469, 2018.

PRIETO-SANDOVAL, V.; ALFARO, J. A.; MEJÍA-VILLA, A.; ORMAZABAL, M. ECO-labels as a multidimensional research topic: trends and opportunities. Journal of Cleaner Production, vol. 135, p. 806-818, 2016.

RABINOVICI, A. Ambientalismo, organizações não governamentais e a busca pela sustentabilidade no turismo. Turismo em Análise, vol. 22. n. ${ }^{\circ}$ 1, São Paulo, 2011. 
REIS, C. N. A responsabilidade social das empresas: o contexto brasileiro em face da ação consciente ou do modernismo do mercado?. Revista Econômica Contemporânea, vol. 11, n. ${ }^{\circ}$ 2, p. 279305, Rio de Janeiro, 2007.

RESPONSIBLE TRAVEL. World responsible tourism awards. Disponível em: $<$ https://www.responsibletravel.com/holidays/responsible-tourism/travel-guide/responsibletourism-awards>. Acesso em: $10 \mathrm{dez} .2018$.

ROCHA, J. M. Desenvolvimento e sustentabilidade do turismo: preceitos da teoria da capacidade de carga turística. Revista do Programa de Pós-Graduação em Turismo, vol. 3, n. ${ }^{\circ}$ 3, Rio Grande do Sul, 2011.

SACHS, I. Caminhos para o desenvolvimento sustentável. Rio de Janeiro: Garamond, 2000.

- Desenvolvimento includente, sustentável, sustentado. Rio de Janeiro: Garamond, 2004.

SANTOS, J. C. S. Conhecimentos e habilidades para a competência gerencial: que conhecimentos e habilidades o gerente deve possuir para alcançar o sucesso? quais as principais habilidades gerenciais?. Disponível em: $<$ http://www.administradores.com.br/artigos/negocios/conhecimentos-e-habilidades-para-acompetencia-gerencial/51712/>. Acesso em: 3 jul. 2017.

SASIDHARAN, V.; SIRAKAYA E.; KERSTETTER, D. Developing countries and tourism ecolabels. Annals of Tourism Research, p. 161-174, 2002.

SERPA, D. A. F.; FOURNEAU, L. F. Responsabilidade social corporativa: uma investigação sobre a percepção do consumidor. Revista de Administração Contemporânea, vol. 11, n. ${ }^{\circ}$ 3, p. 83103, jul./set. 2007.

SOUZA, F. M.; COSTA, H. A. Razões que levam micro e pequenas empresas de ecoturismo ao comportamento responsável na Chapada dos Veadeiros GO. Revista Brasileira de Ecoturismo, vol. 9, p. 93-111, 2016.

SWARBROOKE, J. Turismo sustentável: turismo cultural, ecoturismo e ética. 2. ed. Trad. Saulo Krieger. São Paulo: Aleph, 2000, vol. 5.

TENÓRIO, F. G.; DO NASCIMENTO, F. C. P.; FARES, J.; FERRARI, J.; VILLAR, L. B.; BARROS, R. P. M.; HILST, S. M.; LAZARI, S. Responsabilidade social empresarial: teoria e prática. 2. ed. Rio de Janeiro: FGV, 2006.

UNWTO. Awards for excellence and innovation in tourism. Disponível em: $<$ http://know.unwto.org/content/unwto-awards-excellence-and-innovation-tourism>. Acesso em: 13 jul. 2017.

. Close to one billion international tourists in the first nine months of 2016. Disponível em: $<$ http://media.unwto.org/press-release/2016-11-07/close-one-billion-international-tourists-firstnine-months-2016>. Acesso em: 13 jul. 2017.

14th UNWTO Awards. Disponível em: <http://know.unwto.org/14th-unwto-awardsevents>. Acesso em: 10 dez. 2018.

WTTC. Economic impact analysis. Disponível em: <https://www.wttc.org/research/economicresearch/economic-impact-analysis/>. Acesso em: 13 jul. 2017. 
What are the tourism for tomorrow awards?. Disponível em: $<$ https://www.wttc.org/tourism-for-tomorrow-awards/about-the-awards $>$. Acesso em: $10 \mathrm{dez}$. 2018. 